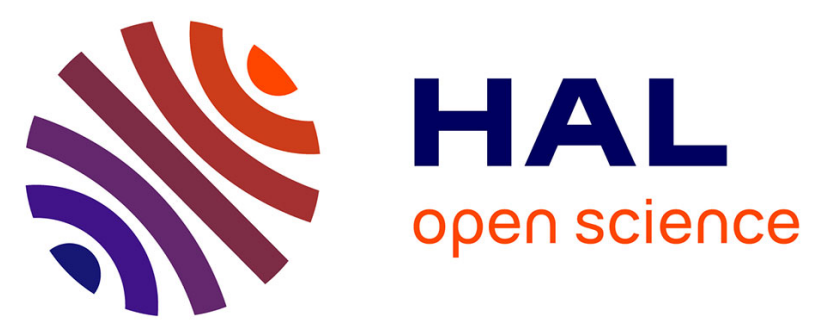

\title{
The Hunt for the Closed Conformation of the Fruit-Ripening Enzyme \\ 1-Aminocyclopropane-1-carboxylic Oxidase: A Combined Electron Paramagnetic Resonance and Molecular Dynamics Study
}

Eugénie Fournier, Sybille Tachon, Nicholas J Fowler, Guillaume Gerbaud, Pascal Mansuelle, Pierre Dorlet, Sam P de Visser, Valérie Belle, A. Jalila Simaan, Marlène Martinho

\section{To cite this version:}

Eugénie Fournier, Sybille Tachon, Nicholas J Fowler, Guillaume Gerbaud, Pascal Mansuelle, et al.. The Hunt for the Closed Conformation of the Fruit-Ripening Enzyme 1-Aminocyclopropane-1carboxylic Oxidase: A Combined Electron Paramagnetic Resonance and Molecular Dynamics Study. Chemistry - A European Journal, 2019, 25 (60), pp.13766-13776. 10.1002/chem.201903003 . hal02303326

\section{HAL Id: hal-02303326 \\ https://hal.science/hal-02303326}

Submitted on 3 Mar 2021

HAL is a multi-disciplinary open access archive for the deposit and dissemination of scientific research documents, whether they are published or not. The documents may come from teaching and research institutions in France or abroad, or from public or private research centers.
L'archive ouverte pluridisciplinaire HAL, est destinée au dépôt et à la diffusion de documents scientifiques de niveau recherche, publiés ou non, émanant des établissements d'enseignement et de recherche français ou étrangers, des laboratoires publics ou privés. 


\title{
The hunt for the closed conformation of the fruit-ripening enzyme 1-amino-cyclopropane-1-carboxylic oxidase: A combined EPR and MD study.
}

\author{
Eugénie Fournier, ${ }^{[a, b]}$ Sybille Tachon, ${ }^{[a]}$ Nicholas J. Fowler, ${ }^{[c]}$ Guillaume Gerbaud ${ }^{[b]}$ Pascal Mansuelle, ${ }^{[\mathrm{d}]}$ \\ Pierre Dorlet, ${ }^{[b]}$ Sam P. de Visser, ${ }^{*[c]}$ Valérie Belle ${ }^{[b]}$ A. Jalila Simaan ${ }^{*[a]}$ and Marlène Martinho ${ }^{*[b]}$
}

\begin{abstract}
ACCO is a non-heme iron(II) containing enzyme involved in the biosynthesis of the phytohormone ethylene, which regulates fruit ripening and flowering in plants. The active conformation of ACCO, and in particular that of the C-terminal part, remains unclear and open and closed conformations have been proposed. In this paper we report on our combined experimental and computational studies to understand the conformation and dynamics of the Cterminal part. We have used Site-Directed Spin-Labelling coupled to Electron Paramagnetic Resonance (SDSL-EPR) spectroscopy. Mutagenesis experiments were performed to generate active enzymes bearing two paramagnetic labels (nitroxide radicals) anchored on cysteine residues, one on the main core and one on the C-terminal part. Inter-spin distance distributions were measured by pulsed EPR and compared with molecular dynamic simulations. Our results reveal the existence of a flexibility of the $\mathrm{C}$-terminal part. This flexibility generates several conformations of ACCO C-terminal part that neither correspond to the existing crystal structures nor to the modelled structures. This highly dynamic region of ACCO raises questions on its exact function during enzymatic activity.
\end{abstract}

\section{Introduction}

The simplest unsaturated hydrocarbon, ethylene, is an essential plant hormone involved in a wide range of physiological and development processes that ranges from vegetative growth, climacteric fruits ripening, root development to mediation of stress

[a] Dr. E. Fournier, Dr. S. Tachon, Dr. A.J. Simaan Aix Marseille Univ, CNRS, Centrale Marseille, iSm2, Marseille France

E-mail: jalila.simaan@univ-amu.fr

[b] Dr. E. Fournier, Dr. G. Gerbaud, Dr. P. Dorlet, Prof. V. Belle, Dr. M. Martinho

Aix Marseille Univ, CNRS, BIP, Marseille, France E-mail: marlene.martinho@univ-amu.fr

[c] Dr N.J. Fowler, Dr S.P. de Visser

Manchester Institute of Biotechnology and School of Chemical Engineering and Analytical Science

The University of Manchester

131 Princess Street, Manchester M1 7DN, United Kingdom

E-mail: sam.devisser@manchester.ac.uk

[d] Dr. P. Mansuelle

Aix Marseille Univ, CNRS, FR3479 Institut de Microbiologie de la Méditerranée, Plate-forme Protéomique, Marseille Protéomique (MaP), IBiSA labelled, Marseille, France

Supporting information for this article is given via a link at the end of the document. responses. ${ }^{[1]}$ 1-amino-cyclopropane-1-carboxylic oxidase (ACCO) is a non-heme iron(II) enzyme that is responsible for the last step of ethylene biosynthesis in plants. The substrate, 1aminocyclopropane-1-carboxylic acid (ACC) is transformed into ethylene by ACCO through a two-electron oxidation with cyanide and carbon dioxide as by-products (Scheme 1). ${ }^{[2-5]}$ The reaction requires ascorbate (as electron donor) and dioxygen. Carbon dioxide (or bicarbonate) is also known to be essential to the reaction, although its function has yet to be determined..$^{[6-8]}$ ACCO is, therefore, a complex enzymatic system that requires many cofactors and co-substrates to function and for which the mode of action is not well understood.

$$
\chi_{\mathrm{NH}_{3}{ }^{+}}^{\mathrm{COO}-}+\mathrm{O}_{2}+2 \mathrm{e}^{-}+2 \mathrm{H}^{+} \underset{\mathrm{CO}_{2} / \mathrm{HCO}_{3}^{-}}{\stackrel{\mathrm{ACCO}-\mathrm{Fe}(\mathrm{II})}{\longrightarrow}} \|+\mathrm{HCN}+\mathrm{CO}_{2}+2 \mathrm{H}_{2} \mathrm{O}
$$

Scheme 1. Chemical reaction of ACC into ethylene catalyzed by ACCO

Knowledge about the structure and the dynamics of a protein is essential for understanding its mechanism and biological function. Currently, there are remaining questions on the active structure of ACCO. The first crystal structure of ACCO was reported for Petunia hybrida ACCO (PhACO1). ${ }^{[9]}$ The structure revealed a core folded in a double-stranded- $\beta$-helix (DSBH) or $\beta$-barrel, surrounded by $\alpha$-helices (Figure 1 ). The active site $\mathrm{Fe}(\mathrm{II})$ ion is coordinated by the side chains of $\mathrm{H} 177, \mathrm{H} 234$ and D179 in a 2histidine 1-carboxylate facial triad, a classical motif highly conserved among non-heme Fe(II)-dependent enzymes. ${ }^{[10]}$ Although active as a monomer, PhACO1 has been crystallized as a homotetramer with the $\mathrm{C}$-terminal part interlocking with the $\mathrm{C}$ terminal part of an adjacent monomer by means of both hydrophobic and electrostatic interactions. The C-terminal part is therefore positioned away from the active site, leaving it rather accessible. Hence, we will refer to this crystal structure as the "open" conformation of ACCO (Figure 1A). It has been shown that the C-terminal region is essential for the enzymatic activity and C-terminal truncated enzymes are poorly active. ${ }^{[9,11]}$ In addition, several residues of this part of the enzyme (e.g. K297 and R300) are important for cofactor's binding. ${ }^{[9,12,13]}$ As such, it has been suggested that the open conformation does not represent an active conformation of the enzyme. Taking these findings into account, structural models of ACCO from apple and then from tomato have been constructed with the C-terminal part folded towards the protein core in a "closed" conformation (Figure 1B). ${ }^{[13,14]}$ 

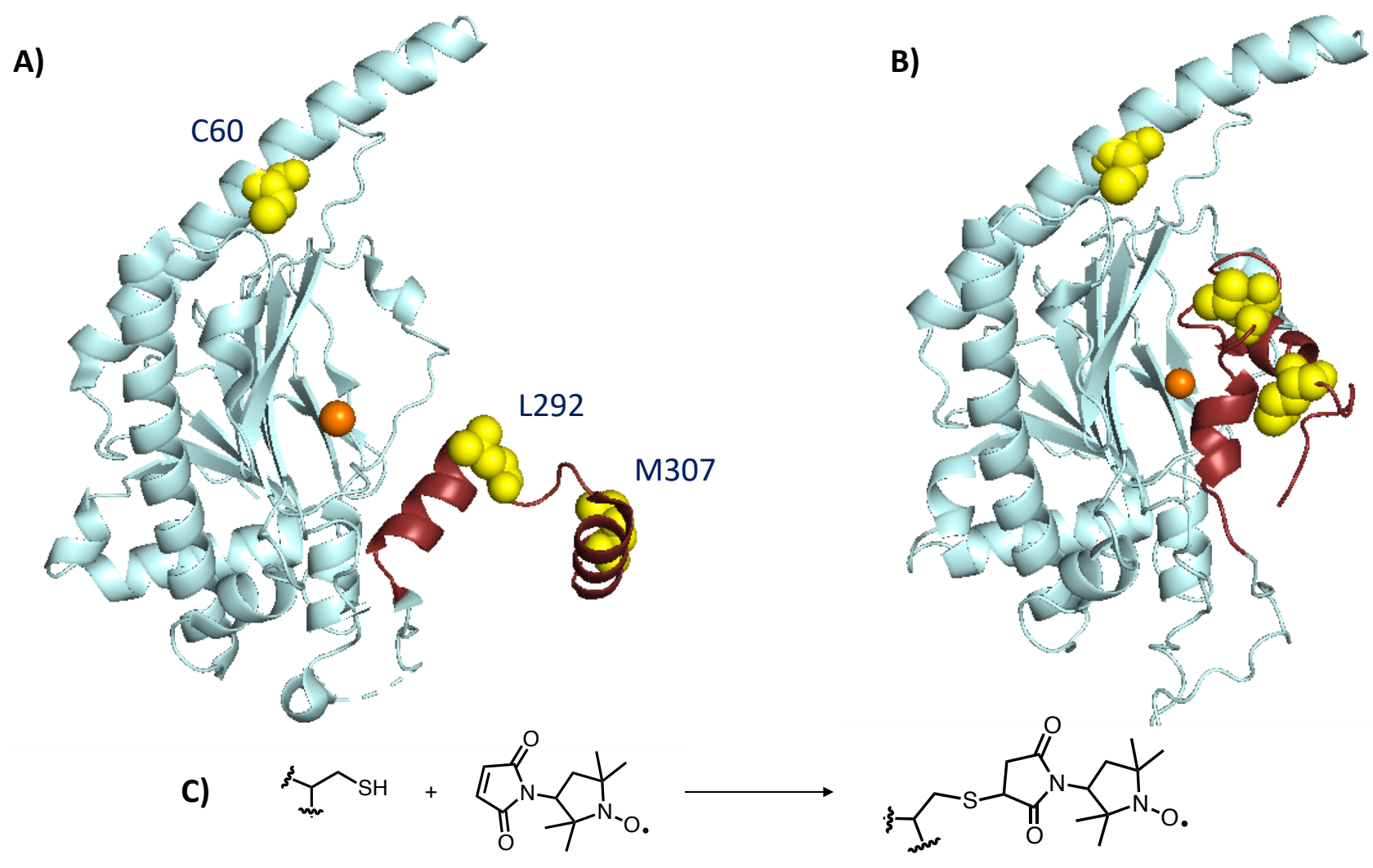

Figure 1. A) X-ray structure of ACCO from P. hybrida (pdb code 1WA6) or "open" conformation and B) modelled structure of ACCO from tomato or "closed" conformation. ${ }^{[14]}$ The C-terminal region starting at residue V281 is highlighted in red, the residues that will be used to anchor spin labels are highlighted in yellow and the iron ion is represented as an orange sphere; $C$ ) labelling reaction of cysteine residues with proxyl (P).

Very recently, two structures of Zn-reconstituted ACCO from Arabidopsis thaliana (AtACO2) have been reported in which the enzyme is found monomeric. ${ }^{[15]}$ For the main part, the structures are highly similar to that of PhACO1 with the $\mathrm{Zn}(\mathrm{II})$ ion bound to the facial triad, in place of the native iron ion. One main difference lies in the C-terminal part that adopts an intermediate conformation between the above-mentioned "open" and "closed" ones. It is however important to note that AtACO2 has been crystallized in a C-terminal truncated form (303 amino acids over 320 full length). The lack of the extremity of the C-terminal part may have an influence on both the conformation and the activity of the enzyme. ${ }^{[9,11]}$ Overall, these structural differences might reflect a flexibility of the C-terminus possibly important for the activity of ACCO enzymes.

Site-directed spin-labelling (SDSL) followed by Electron Paramagnetic Resonance (EPR) spectroscopy has emerged as a powerful tool to probe conformation and dynamics of proteins. ${ }^{[16-}$ 19] This technique relies on the covalent insertion of one (or several) stable paramagnetic probe(s) at a selected site of a protein, often a cysteine residue introduced by site-directed mutagenesis. SDSL-EPR allows to probe the micro-environment of the spin label at the residue level or to measure inter-label distances in the range of typically $1.8-8.0 \mathrm{~nm}$ using pulsed-EPR techniques such as Double Electron-Electron Resonance (DEER) experiment (distances up to $16 \mathrm{~nm}$ have now been reported when full deuteration of the protein sample is achieved). ${ }^{20,21]}$
Given their relatively low abundance in protein sequences and their well-mastered chemical reactivity, cysteine residues are often used for chemical modification of proteins. ${ }^{[22,23]}$ We have chosen to introduce a nitroxide radical (3-maleimido-2,2,5,5tetramethyl-1-pyrrolidinyloxy or proxyl $(\mathbf{P})$ ) on cysteine residues of ACCO (Figure 1C). Tomato ACCO contains four cysteine residues $(\mathrm{C} 28, \mathrm{C} 60, \mathrm{C} 133$ and $\mathrm{C} 165)$ in the sequence that are located on the main core of the protein. In a previous study, we have reported on mutagenesis experiments to systematically replace native cysteines by other amino acids in order to reduce the number of cysteines for chemical modification. ${ }^{[11]}$ We have also shown that several positions are suitable for the introduction of cysteines on the C-terminal part of the enzyme without losing activity (in particular L292C and M307C mutants were successfully produced and chemically modified). However, continuous-wave (cw) EPR spectra were found complex and not informative to monitor conformational changes upon addition of the different cofactors. We therefore directed our efforts towards inter-label distance measurements by pulsed-EPR techniques. In this manuscript we report on our combined experimental and computational studies to understand the conformation and dynamics of the C-terminal part of the enzyme. Based on our preliminary results, ${ }^{[11]}$ we have generated variants displaying two accessible cysteines residues (one on the main core and one on the C-terminal part) and introduced a paramagnetic probe $(\mathbf{P})$. DEER experiments were performed to measure inter-spin distance distributions under several conditions, and in particular 
upon addition of cofactors. Molecular dynamic simulations were performed in order to bring complementary information. Both experimental and computational data reveal a flexibility of the Cterminal part of ACCO irrespective of the experimental conditions. Our studies highlight the combined use of SDSL-EPR with computational modelling as a useful tool for protein dynamics investigation.

\section{Results and Discussion}

\section{Choice of the labelling positions.}

In order to gain conformational information on the C-terminal region of the enzyme using distance distribution measurements by DEER, a pre-requisite lies in the generation of doubly modified enzymes bearing one spin label on the main core and one on the C-terminal part. ACCO from tomato contains four cysteines on the main core: $\mathrm{C} 28, \mathrm{C} 60, \mathrm{C} 133$ and $\mathrm{C} 165$. In a previous study, we have shown that only two of the existing native cysteines are accessible to the $\mathbf{P}$ label: $\mathrm{C} 60$ and $\mathbf{C} 165 .^{[11]}$ We have then performed a complete mutagenesis study to provide proteins displaying unique modification sites on the main core while retaining their primary structure and function. Two mutants have been selected: $\mathrm{C} 60 \mathrm{Y}$ and $\mathrm{C} 165 \mathrm{H}$. Chemical modification of the C60Y enzyme, i.e. introduction of a label on the $\mathrm{C} 165$ position (C165*; the notation * will be used all along the text referring to the presence of the label) led to a completely inactive enzyme. Thus the $\mathrm{C} 165 \mathrm{H}$ variant, which remains active after labelling, appeared as the best candidate to introduce a label on the main core $\left(\mathrm{C}^{*} 0^{*}\right)$. We have also shown that introduction of a cysteine on the C-terminal region provided fully functional enzymes and two positions were selected (L292 and M307).

In order to verify that the above-mentioned positions are suitable for conformational studies, we used MMM software (Multiscale Modelling of Macromolecules), an open-source modelling toolbox that can compute distance distributions between spin labels attached to a protein having an available pdb description. ${ }^{[24]}$ The P labels were introduced on cysteines at positions 60, 292 and 307 using either the "open" or "closed" conformations. The number of rotamers of $\mathbf{P}$ that each labelled variant can experience was calculated while the structure of the enzyme remained fixed (Figure 2A and Table S1). These rotamers were used to predict the inter-spin distance distributions between labels introduced at position C60-C292 or C60-C307. The calculated distance distributions for the open and closed conformations appear quite different (Figure 2B) and measuring $\mathrm{C} 60^{*}-\mathrm{C} 292^{*}$ and $\mathrm{C} 60^{*}-\mathrm{C} 307^{*}$ distances seems pertinent to discriminate the two conformations.
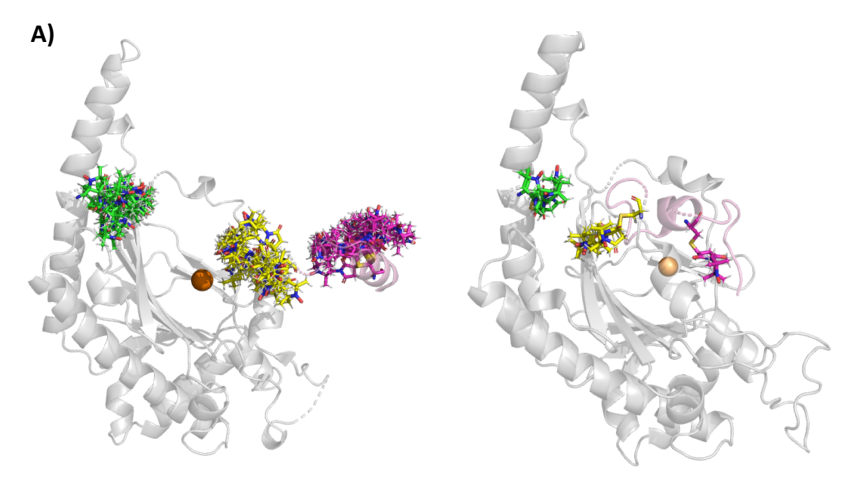

B)
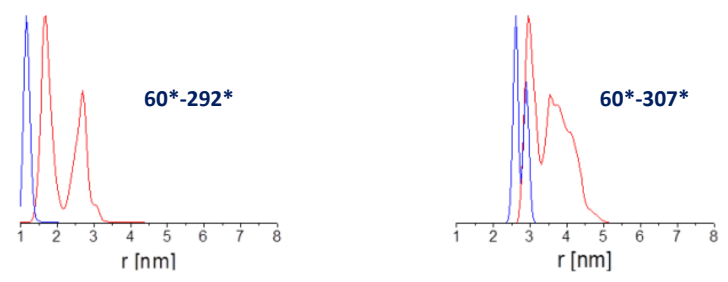

Figure 2. (A) MMM computed spin label rotamers attached to the cysteines at positions C60 (green), C292 (yellow) and C307 (pink) for the "open" (left) and "closed" (right) conformations (B) calculated inter-label distance distributions for the "open" (red) and "closed" (blue) conformations for C60*-C292* (left panel) and $\mathrm{C} 60^{*}-\mathrm{C} 307^{*}$ (right panel) distances.

\section{Mutagenesis and chemical modification with $\mathbf{P}$}

We have generated double mutants: C165H/L292C and $\mathrm{C} 165 \mathrm{H} / \mathrm{M} 307 \mathrm{C}$. The enzymes were expressed and purified according to previously reported procedures. ${ }^{[11,14,25]}$ Labelling experiments were conducted using $\mathbf{P}$ spin label (Figure $1 \mathrm{C}$ ) and the labelled enzymes were analysed by mass spectrometry (MS) to confirm the introduction of the two labels at the desired positions, namely $\mathrm{C} 60^{*} \mathrm{C} 292^{*}$ and $\mathrm{C} 60^{*} \mathrm{C} 307^{*}$ (Table S2). Far-UV $\mathrm{CD}$ spectra of native, double mutants and labelled enzymes were recorded to ensure that the mutations did not impact their global secondary structures (Figure S1). Specific activities of the unlabelled and labelled enzymes were measured by detection of the ethylene production (Figure 3 ). The double mutants display activities that range between 45 to $60 \%$ compared to the native enzyme and between 60-70\% compared to the single $\mathrm{C} 165 \mathrm{H}$ mutant. No significant effect of labelling was observed on the activity.

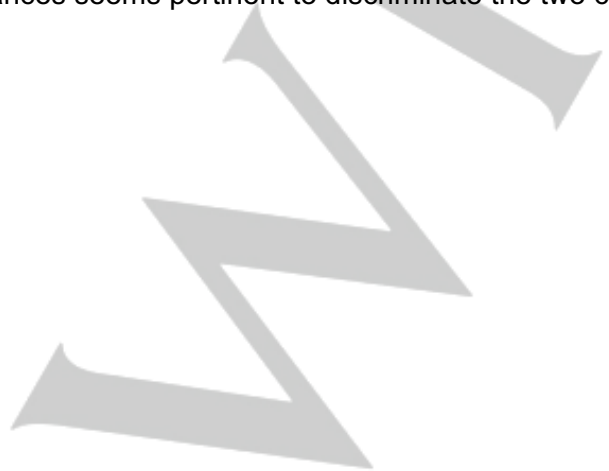


WILEY-VCH

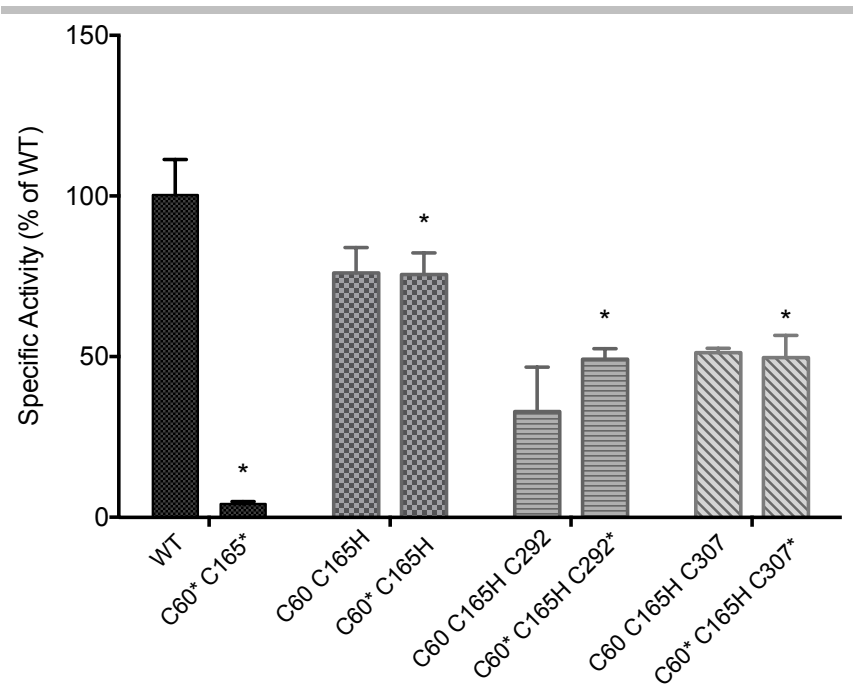

Figure 3. Specific activities of native ACCO (\% relative to the native enzyme) and mutants before and after labelling with proxyl $(\mathbf{P})$. Values are derived from means \pm SD of at least three repeated experiments.

\section{DEER experiments in absence of cofactors.}

The experiments were first conducted on the enzymes in absence of substrates or cofactors. Q-band DEER traces and the resulting distance distributions are shown in Figures 4 and 5. For the C60*C292* enzyme, a bimodal distance distribution was obtained with two maxima at 3.4 and $4.5 \mathrm{~nm}$ (Figure $4 \mathrm{~A}$ and Figure S2). In the case of $C 60^{*} \mathrm{C} 307^{*}$, the results gave a very broad distance distribution with a maximum centred at $4.1 \mathrm{~nm}$, and a shoulder at $3.0 \mathrm{~nm}$ (Figure 5A and Figure S2). Noteworthy, the experimental distance distributions are very different from the ones predicted using MMM software for both mutants and conformations. These results suggest that the ACCO conformations derived from the crystal or modelled structures may not be the ones observed in solution. In addition, although two maxima are clearly present (Figure S2), the experimental distance distributions are broad and populate a range of distances higher than the MMM calculated ones. These results reveal that the C-terminal part of ACCO can probably adopt several conformations and suggest a flexibility of this region.

DEER experiments in presence of cofactors/substrates (ACC, $\mathrm{HCO}_{3}{ }^{-}$and ascorbate) without dioxygen.

ACCO requires several substrates (ACC, $\mathrm{O}_{2}$ and ascorbate) and a cofactor (bicarbonate or $\mathrm{CO}_{2}$ ) to function. To date, few structural data have been reported on the binding of the different cofactors/substrates at the active site. Using EPR and ENDOR spectroscopies on a $\mathrm{Fe}$ (II)-NO complex (in which NO potentially binds on the iron in the place of $\mathrm{O}_{2}$ ), it has been shown that ACC binds to the $\mathrm{Fe}$ (II) ion in a bidentate fashion via the nitrogen of the amine and an oxygen of the carboxylate group. ${ }^{[25]}$ Recently, an ACC bound structure of PhACO1 (in the tetrameric crystal form) reconstituted with $\mathrm{Ni}(\mathrm{II})$ has been released in which a bidentate binding mode of ACC on the $\mathrm{Ni}$ ion is observed (pdb 5TCV). Binding of other cofactors/substrates in the active pockets still remains under debate. Using modelling studies, it has been proposed that K297 and R300 from the C-terminal part, are involved in ascorbate and/or bicarbonate binding. ${ }^{[13,14]}$
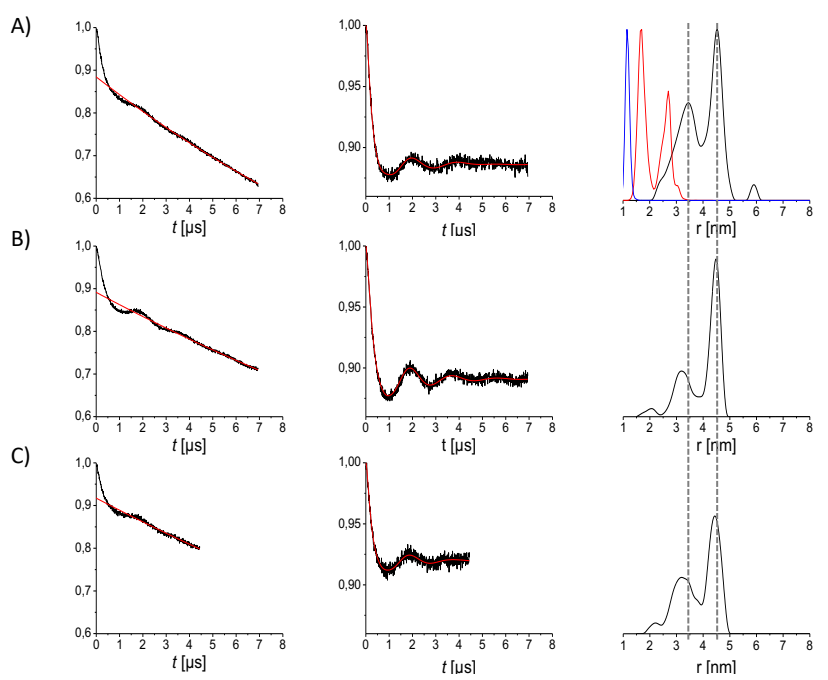

Figure 4. Left panel. Experimental Q-band DEER traces recorded at $60 \mathrm{~K}$ for $(\mathrm{A})$ $\mathrm{C}^{\circ} 0^{*} \mathrm{C} 292^{*}(\mathrm{~B})$ in the presence of $\mathrm{ACC}$ and $\mathrm{HCO}_{3}{ }^{-}$and $(\mathrm{C})$ in the presence of ACC, $\mathrm{HCO}_{3}^{-}$and ascorbate. Red lines indicate the baseline used for background correction. Middle panel. Corrected DEER traces with superimposed fits derived from Tikhonov regularization. Right panel. Tikhonovderived distance distributions obtained using DeerAnalysis 2015 and calculated distance distributions for the "open" (red) and "closed" (blue) conformations obtained using MMM. Vertical dashed lines are a guide for the reader eye.

To examine whether binding of cofactors in the active site could influence the conformation of the C-terminal part, DEER experiments were performed on labelled ACCO mixed with successive addition of co-factors ( $\mathrm{ACC}, \mathrm{HCO}_{3}{ }^{-}$and ascorbate). The different distance distributions are shown in Figure 4 and 5 for the two labelled variants. Note that ascorbate is able to reduce nitroxides into hydroxylamine (EPR-silent) and was therefore added at the last moment. Despite this, in some cases, time traces recorded in presence of ascorbate display a lower modulation depth probably arising from a decrease of spin concentration due to partial reduction of the labels.

In the case of $\mathrm{C}^{\circ} 0^{*} \mathrm{C} 292^{*}$ (Figure 4), no drastic change is observed with the distance distribution profiles, which remain overall similar to the one obtained without any cofactor. The long distance distribution centred at $4.5 \mathrm{~nm}$ is not modified upon substrates / cofactors addition. A small shift of the second maximum is however detected going from $3.4 \mathrm{~nm}$ (alone) to 3.1 $\mathrm{nm}$ upon addition of ACC and bicarbonate (Figure 4B and Figure S3). The distance distribution is not significantly modified upon further addition of ascorbate (Figure 4C). Furthermore, a change in the relative amplitudes of the two populations is observed, suggesting that the population at lower distance becomes less important. Note that a narrowing of the distributions is observed possibly suggesting that addition of cofactors leads to a selection of conformations that were already present.

In the case of the $\mathrm{C} 60^{*} \mathrm{C} 307^{*}$ enzyme, the main distance distribution centred at $4.1 \mathrm{~nm}$ is not affected by the addition of cofactors (Figure 5B, 5C and Figure S3). The shoulder at $3.1 \mathrm{~nm}$ becomes broader and less defined in presence of cofactors. Note that distance distributions at larger values $(\geq 6 \mathrm{~nm}$ ) are not significant because located in high uncertainty region. Surprisingly, addition of ascorbate did not impact the modulation depth like in the previous case (Figure $5 \mathrm{C}$ ) maybe reflecting a 
lower accessibility of the spin label grafted at position 307 to the reductant as compared to the one at 292.

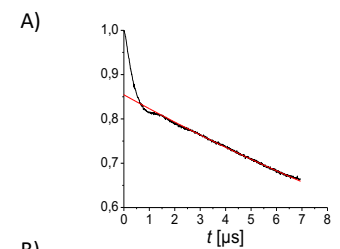

B)
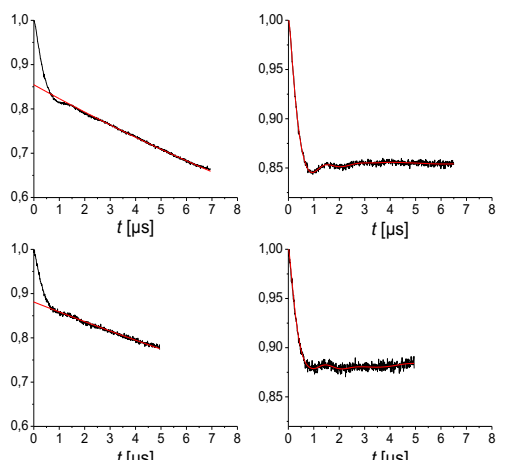

C)
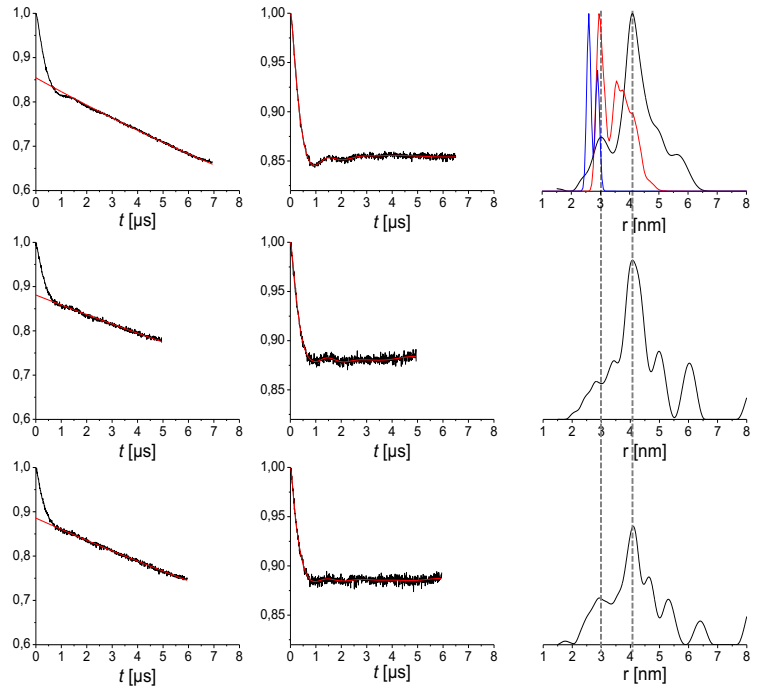

$t[\mu \mathrm{s}]$

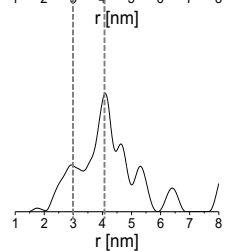

Figure 5. Left panel. Experimental Q-band DEER traces recorded at $60 \mathrm{~K}$ for (A) $\mathrm{C} 60^{*} \mathrm{C}_{307}{ }^{*}(\mathrm{~B})$ in the presence of $\mathrm{ACC}$ and $\mathrm{HCO}_{3}{ }^{-}$and $(\mathrm{C})$ in the presence of $\mathrm{ACC}, \mathrm{HCO}_{3}^{-}$and ascorbate. Red lines indicate the baseline used for background correction. Middle panel. Corrected DEER traces with superimposed fits derived from Tikhonov regularization. Right panel. Tikhonovderived distance distributions obtained using DeerAnalysis 2015 and calculated distance distributions for the "open" (red) and "closed" (blue) conformations obtained using MMM. Vertical dashed lines are a guide for the reader eye.

\section{DEER experiments in presence of cofactors/substrates (ACC,} $\mathrm{HCO}_{3}{ }^{-}$and ascorbate) and dioxygen.

The samples were prepared anaerobically and then opened to air for 2 minutes. The DEER spectra were then recorded (Figure S4). For both mutants, the main distance distribution around $4 \mathrm{~nm}$ observed in the previous conditions remains unchanged. Several distributions appear at lower distances ranging from 2 to $4 \mathrm{~nm}$. It has to be noted that different species can be generated upon catalytic turn-over rendering the fine interpretation of these data difficult. Overall, for both variants and in all conditions, the distance distributions remain very broad, suggesting that the $\mathrm{C}$ terminal part of ACCO keeps its flexibility even in the presence of its cofactors.

\section{Study of the core enzyme flexibility by pulsed EPR experiments}

In order to get additional information on the dynamics of the protein and to find out whether the flexibility of the enzyme was limited to the C-terminal tail only or included the main body as well, we conducted two additional experiments to measure distances on the main body using pulsed-EPR experiments: (i) a nitroxidenitroxide distance and (ii) a metal-nitroxide distance.

Firstly, we used the native enzyme that bears nitroxide labels on the $\mathrm{C} 60$ and $\mathrm{C} 165\left(60^{*} 165^{*}\right)$. The data are presented in Figure S5. A single distance distribution is detected centred at $2.6 \mathrm{~nm}$. Secondly, we used a copper(II)-reconstituted enzyme with the metal ion as a spectroscopic probe. We have indeed previously reported that $\mathrm{Cu}(\mathrm{II})$ binds at $\mathrm{ACCO}$ active site with an affinity similar to that of the native iron ion. ${ }^{[26]}$ We thus reconstituted the singly $\mathrm{C} 60^{*}$ labelled enzyme with $\mathrm{Cu}(\mathrm{II})$ and used the RIDME sequence, a pulsed EPR sequence particularly well-suited to determine distances between paramagnetic metal centres and radicals. ${ }^{[27]} \mathrm{A}$ main $\mathrm{Cu}-\mathrm{C} 60^{*}$ distance distribution is found centred at $2.9 \mathrm{~nm}$ with a shoulder at $2.0 \mathrm{~nm}$ (Figure S6). In both cases, the distance distributions are less complex and large than the distributions measured with a label on the C-terminal part, which suggests that the main body is less dynamic than the C-terminal part. Using MMM software, the manually estimated distances between the metal and different conformers of the nitroxide range from 1.8 to $2.4 \mathrm{~nm}$ for the closed form and 2.1 to $2.5 \mathrm{~nm}$ for the open form. The RIDME data are thus in good enough agreement with the two forms. This confirms that the conformation of the main body is not affected by the flexibility of the $\mathrm{C}$-term part of the protein.

Molecular Dynamics simulations on the 'open' and 'closed' forms.

To gain more insight into the conformational landscape of the Cterminal tail region of ACCO we performed molecular dynamics simulations of the $\mathrm{C} 60^{*} \mathrm{C} 292^{*}$ and $\mathrm{C}^{*} 0^{*} \mathrm{C} 307^{*}$ variants and started from both open and closed conformations. Model structures in an open conformation were created using the 1WA6 pdb structure with missing residues, hydrogen atoms, solvent and paramagnetic probes added as described in the Methods Section. Model structures in a closed conformation were created using the previously published model structure with missing hydrogen atoms, solvent, paramagnetic probes and cofactors added as specified below. ${ }^{[28]}$ Three molecular dynamics simulations were performed for each variant for a total simulation time of $1.2 \mu \mathrm{s}$ for open conformations and $0.6 \mu \mathrm{s}$ for closed conformations respectively. Every $0.1 \mathrm{~ns}$ the distance between the $\mathrm{O}$ atoms of the two paramagnetic probes was measured in order to produce inter-spin distance distributions for comparison to the experimentally determined distributions.

The computed $\mathrm{Fe}-\mathrm{C} 60^{*}$ distances are similar for the simulations starting from the open and closed forms (Figure S7) and are found centred around 2.3-2.4 $\mathrm{nm}$. These distances are in good agreement with the RIDME experiment. As mentioned above, this supports the fact that the main core of the protein is rather rigid and that no major differences are expected on this part while the C-terminal part varies.

In Figure 7, the computed inter-spin distance distribution for the open (green line) and closed (red line) form of $\mathrm{C} 60^{*} \mathrm{C} 292^{*}$ is compared against the experimentally determined distributions without (solid black line) and with cofactors (dashed black line) included. The open form recreates the broad range seen in experiment with maxima in a similar range to those reported above. Therefore, the MD simulations give a good representation of the experimental system and confirm that the C-terminal tail region of $\mathrm{ACCO}$ is indeed flexible. However, our calculations suggest that the separation of tagged Cysteines in the closed form appear at shorter distances of around $1.7 \mathrm{~nm}$. Although when experiments are performed in the presence of co-factors, a distribution centred around $3 \mathrm{~nm}$ is detected, this distance is too long to match the computed distance for the closed form. This could mean that either the closed form is too tight or that this closed form was not actually observed in our experiments. 


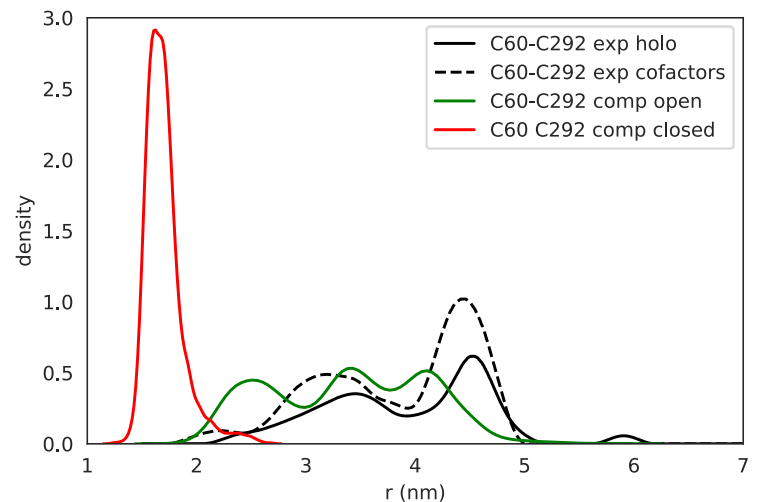

Figure 7. Inter-spin distance distributions extracted from molecular dynamics simulations for the open (green line) and closed (red line) form of C60 C292 are compared against the experimentally determined distributions in absence (solid black line) and in presence of $\mathrm{ACC}, \mathrm{HCO}_{3}^{-}$and ascorbate (dashed black line).

Next, we computed the inter-spin distance distributions for the open and closed forms of $\mathrm{C} 60^{*} \mathrm{C} 307^{*}$ to compare to the experimentally determined distributions (Figure 8). Again, we see that the broad range of tagged Cysteines distances are reasonably well captured in our simulations, but that in this instance the maxima do not match. This could highlight the need for more sampling due to the tag at $\mathrm{C} 307$ being located further towards the C-terminus where it will likely be more mobile in comparison to the tag at C292. In our experiments, the addition of cofactors resulted in a distribution to appear at $2 \mathrm{~nm}$ and an increase at $3 \mathrm{~nm}$, which could represent an increase in population of the closed form ACCO. The simulations of the closed form do not give distances at $2 \mathrm{~nm}$ but a distance distribution with a range from $2.5-4 \mathrm{~nm}$. Although the presence of the closed form cannot be excluded, it seems difficult to conclude on its presence from the $\mathrm{C} 60^{*} \mathrm{C} 307^{*}$ distance distributions.

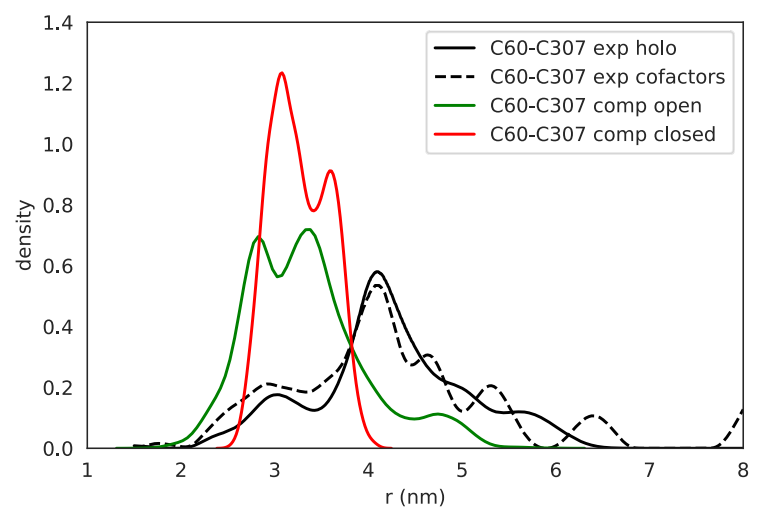

Figure 8 Inter-spin distance distributions extracted from molecular dynamics simulations for the open (green line) and closed (red line) form of C60 C307 are compared against the experimentally determined distributions in absence (solid black line) and in presence of $\mathrm{ACC}, \mathrm{HCO}_{3}{ }^{-}$and ascorbate (dashed black line).

Overall, the distances between probes computed by our simulations of the open form of both ACCO variants agree rather well with experiment, whereas the distances between probes computed for the closed form do not match those observed experimentally. This suggests that either the closed form has not been observed in experiment or that our computational model of the closed form is too tightly closed. An alternative explanation could be proposed by considering the motion of the C-terminal region in our simulations (see movies of trajectories of open form provided in the Supporting Information). In all repeats of both variants we see that the C-terminal tail region is initially highly dynamic but that after some time it tends to "bind" to the protein surface and that, in the majority of cases, the $\alpha$-helix at the Cterminus is oriented towards the iron(II) centre. It is therefore possible that ACCO does not close as tightly as suggested in previous models. This could explain why the C-terminal $\alpha$-helix is important for activity but that the experimentally observed distances do not match those computed from a more tightly bound model.

\section{Conclusions}

Under our experimental conditions, no direct evidence of the "closed" conformation could be obtained and the closed form, as proposed by the modelled structures, is clearly not the major form present in solution. MD simulations have pointed out that, starting from the open conformation, the C-terminal part tends to "bind" to the protein surface in a conformation that is not as tightly closed as the proposed modelled structures. ${ }^{[13,14]}$ Several reasons can be evoked to explain this observation: (i) the "closed" conformation does not exist or (ii) the "closed" conformation is only a transient form during the catalytic cycle that could not be detected under our experimental conditions. The latter hypothesis is supported by our MD simulations that indicated that the closed form is stable when the cofactors are present, maintained by electrostatic interactions (e.g. between ascorbate and/or bicarbonate with $\mathrm{K}$ or $\mathrm{R}$ residues from the $\mathrm{C}$-terminal part). This conformation could still be formed under catalytic conditions. Further work is in progress in our laboratories to get further insight into the active conformation (other labelling positions, rapid kinetics, etc.).

The conformation adopted by the C-terminal part does no more correspond to the "open" form derived from crystallographic studies. ${ }^{[9]}$ The wideness of distance distributions (and the fact that several maxima are detected) suggests that the C-terminal part of ACCO is dynamic and adopts different (or a range of) conformations. This is confirmed by our MD simulation that show that starting from the open conformation, the C-terminal part moves around the active site, maintaining distances between the probes at $\mathrm{C} 0^{*}$ and $\mathrm{C} 202^{*}$ or $\mathrm{C}_{307^{*}}$ ranging from $3-4 \mathrm{~nm}$, consistent with experimental data. The existence of two conformations switching from one to the other one upon catalytic events has been proposed for several enzymatic systems. ${ }^{[29,30]}$ However, this two conformations picture is probably a very simple view of enzymatic structure-function complexity. It is now admitted that proteins are dynamic entities that possess inherent flexibility, a fundamental property that allows them to function through molecular interactions with other molecules (either substrates, cofactors or proteic partners). In particular, the presence of a dynamic part adopting a broad range of conformational setpoints has been evidenced in several 
enzymatic systems (e.g. flavin reductases). ${ }^{[1,32]}$ These findings hence raise questions on the exact function of such flexibility on ACCO enzymatic activity.

\section{Experimental Section}

\section{Chemicals}

Unless otherwise noted, all chemicals and solvents were of analytical grade and used without further purification.

\section{Mutagenesis}

ACCO wild-type and variant were constructed from a PET21a (Novagen) plasmid containing the ACCO gene (pTOM13) from Lycopersicum esculentum. ${ }^{[33]} \mathrm{C} 165 \mathrm{H}$ mutant was previously reported. [11] Site-directed mutations of the ACCO $\mathrm{C} 165 \mathrm{H}$ encoding gene were performed by PCR using the already described primers to generate the double mutants C165H_L292C and C165H_M307C. The PCR reactions were performed following our previously described procedure. ${ }^{[11]}$

\section{Overexpression and purification of recombinant apo Lycopersicum esculentum ACCO proteins}

Plasmids encoding for ACCO wild-type and variants were transformed into thermocompetent BL21 (DE3) Escherichia coli cells. Transformants were then subcultured in LB medium containing ampicillin at $37^{\circ} \mathrm{C}(200 \mathrm{rpm})$ to reach an optical density at $600 \mathrm{~nm}\left(\mathrm{OD}_{600}\right)$ of 0.5 . Cells were diluted to 0.05 and grown at $37^{\circ} \mathrm{C}$ in Terrific Broth medium to an $\mathrm{OD}_{600}=1$ before induction with $0.5 \mathrm{mM}$ isopropyl- $\beta$-D-thiogalactopyranoside (IPTG) at $28^{\circ} \mathrm{C}$ during $4 \mathrm{~h}$. Cultures were then harvested by centrifugation at $4^{\circ} \mathrm{C}$ (Sorvall Lynx 6000 , Thermo Scientific) and kept at $-20^{\circ} \mathrm{C}$. Purification steps were performed at $4^{\circ} \mathrm{C}$ using the Akta Purifier FPLC System (GE Healthcare). Thawed cell pellets were resuspended in lysis buffer containing $1 \mathrm{X}$ BugBuster (Merck Millipore), 10\% glycerol, $3 \mathrm{mM}$ EDTA, $5 \mathrm{mM}$ dithiothreitol (DTT) and $1 \mathrm{mM}$ benzamidine, during 30 min under gentle agitation. Cell debris were removed by centrifugation at $18000 \mathrm{~g}$ for $45 \mathrm{~min}$. The supernatant was dialyzed in dialysis tubing (Spectra/por, Spectrumlabs) of 12-14 kD MWCO against buffer A overnight (buffer A: 25 mM 4-(2-hydroxyethyl)-1-piperazineethanesulfonic acid (HEPES) pH 8.0, $10 \%$ glycerol, 3 mM EDTA, 1 m benzamidine, 5 mM DTT). Dialyzed ACCO was loaded on a $Q$ Sepharose resin (Fast Flow Q Sepharose, GE Healthcare) and was eluted with gradient buffer A containing $150 \mathrm{mM} \mathrm{NaCl}$ The fractions containing $90-95 \%$ pure ACCO (according to SDS-PAGE analysis) were pooled, dialyzed against $25 \mathrm{mM}$ HEPES $\mathrm{pH} 7.2,10 \%$ glycerol, and concentrated in a Vivaspin 2, $10 \mathrm{kD} \mathrm{MWCO,} \mathrm{using} \mathrm{a}$ polyethersulfone membrane (Sigma-Aldrich).

\section{Preparation of holo ACCO proteins}

As ACCO was purified as an apo-protein, 0.9 equivalent $\mathrm{Fe}\left(\mathrm{SO}_{4}\right)_{2}\left(\mathrm{NH}_{4}\right)_{2} \cdot 6 \mathrm{H}_{2} \mathrm{O}$ was anaerobically added to a solution of ACCOs to obtain the holo-proteins. All experiments have been performed on the holoproteins, unless otherwise stated.

\section{ACco activity assays}

The activity of ACCO was investigated at $29^{\circ} \mathrm{C}$ in $1.7 \mathrm{~mL}$ hermetically sealed vials. The total assay volume was $200 \mu \mathrm{L}$ of the standard reaction mixture containing $25 \mathrm{mM}$ HEPES at pH 7.5 and $10 \%$ glycerol, $5 \mu \mathrm{g}$ of apo-ACCO, $18 \mathrm{mM} \mathrm{NaHCO}_{3}, 1.25 \mathrm{mM} \mathrm{ACC}, 8 \mathrm{mM} \mathrm{L}$-ascorbic acid and 40 $\mu \mathrm{M} \mathrm{Fe}\left(\mathrm{SO}_{4}\right)_{2}\left(\mathrm{NH}_{4}\right)_{2} \cdot 6 \mathrm{H}_{2} \mathrm{O}$. After 7 min of incubation at $29^{\circ} \mathrm{C}$ with gentle shaking, $1 \mathrm{~mL}$ of the ethylene produced was withdrawn from the headspace by a gas-tight syringe and injected onto a gas chromatograph (Shimadzu GC-2014A equipped with a Poropak Q 80/100 column).
Ethylene was quantified with an external standard ( $1 \%$ ethylene in nitrogen, Scott Mini-Mix, Air Liquide). The specific activity is expressed as the quantity of ethylene produced per minute and per mg of enzyme.

\section{Circular dichroism (CD) spectroscopy}

CD spectra were recorded on a Jasco J-815 spectrometer at room temperature with the use of $0.1 \mathrm{~cm}$ path-length cells in $10 \mathrm{mM}$ sodium phosphate at $\mathrm{pH} 7.5$. The acquisition was performed from 190 to $250 \mathrm{~nm}$ at $20 \mathrm{~nm} \mathrm{~min}{ }^{-1}$ (10 scans). Protein concentration was in the range of 3-10 $\mu \mathrm{M}$. The mean ellipticity values per residue $\left([\theta]_{\mathrm{mrw}, \lambda}\right)$ were calculated as described before. ${ }^{[34]}$

\section{Spin-labelling procedure}

The labelling experiments were performed on the apo-proteins placed in deuterated MOPS $50 \mathrm{mM} \mathrm{pH} 7.5$ and in an ice bath. The proteins (wt and mutants) obtained after purification and concentration were labelled with 3-maleimido-2,2,5,5-tetramethyl-1-pyrrolidinyloxy (Sigma Aldrich) spin label, Proxyl, referred to as P. 100 molar equivalent of DTT were first added to the protein (protein concentration below $250 \mu \mathrm{M}$ to avoid precipitation) to allow reduction of the cysteines. The mixture was then incubated $20 \mathrm{~min}$ in ice. The excess of DTT was removed using a gel filtration desalting PD-10 column (GE Healthcare). The fractions containing the protein (checked by $\mathrm{OD}_{280}$ ) were pooled. Four additions of 10 equivalents $\mathbf{P}$ (from $32 \mathrm{mM}$ stock solution in acetonitrile), spaced by 30 min, were performed. Excess of free spin labels was removed using a second desalting PD-10 column. The fractions containing the labelled ACCO were checked by $\mathrm{CW}$ EPR at room temperature, pooled and concentrated using Vivaspin 2 (Sartorius), $10 \mathrm{kD}$ MWCO to reach a concentration of $\sim 9 \mathrm{mg} \mathrm{ACCO} / \mathrm{mL}$. The spin-labelled enzymes were stored at $-20^{\circ} \mathrm{C}$.

\section{Inter-spin distance predictions using MMM}

The prediction of inter-spin distances of labelled protein was performed with Multiscale Modelling of Macromolecules (MMM) 2017 software from a selected set of label rotamers. ${ }^{[24]}$ The resulting computational rotamers were used to obtain a prediction of the distance distributions between spinpairs by calculated dipolar evolution echo traces of DEER experiments. Predictions were done using the crystal and model structures for the "open" and "closed" conformations.

\section{Mass spectrometry}

Global mass determination. Samples of 20 to 30 pmoles of unlabelled and labelled ACCO enzymes were prepared by dilution in $10 \mu \mathrm{L}$ of $0.1 \%$ trifluoroacetic acid (TFA) in water (v/v). The mixture was then spotted onto a MALDI Target plate $(1 \mu \mathrm{L})$ and saturated solution of $\alpha$-cyano-4hydroxycinnamic acid (HCCA) or sinapinic matrix $(1 \mu \mathrm{L})$ in $70 \%$ acetonitrile in water, $0.1 \%$ TFA (v/v) was added. The global mass was measured on a MALDI-ToF mass spectrometer Microflex II (Bruker Daltonics, Deutschland) in the range from 2000 to $20000 \mathrm{Da}$ and in a linear and positive mode. External mass calibration was performed on the averaged $[\mathrm{M}+\mathrm{H}]^{+}$from the Protein Calibrant I (Bruker Daltonics).

Digestion. Samples of 60 to 100 pmoles were digested by trypsin (Sigma, St Louis, MO, USA) or GluC (Madison, WI, USA) at a ratio enzyme to substrate of $1 / 50(\mathrm{w} / \mathrm{w})$ (Sigma, St Louis, MO, USA) for 4 hours at $37^{\circ} \mathrm{C}$. The digested solutions were then acidified by $1 \mu \mathrm{L}$ of $12.5 \%$ trifluoroacetic acid (TFA) in water $(\mathrm{v} / \mathrm{v})$, vacuum dried and then dissolved in $0.1 \%$ TFA in water $(\mathrm{v} / \mathrm{v})$ before being spotted onto a MALDI Target plate $(1 \mu \mathrm{L})$ and addition of a saturated solution of matrix $\alpha$-cyano-4-hydroxycinnamic acid $(1 \mu \mathrm{L})$ of $70 \%$ acetonitrile in water, $0.1 \%$ TFA $(\mathrm{v} / \mathrm{v})$. Digested peptides were analyzed on the MALDI-ToF mass spectrometer Microflex II from Bruker Daltonics in the range from 600 to $5000 \mathrm{Da}$. Data acquisition was operated in positive and reflectron mode. External mass calibration was performed 
on the mono-isotopic $[\mathrm{M}+\mathrm{H}]^{+}$from the peptide calibration standard (Bruker Daltonics). A peak list was generated by a PMF (Peptide Mass Fingerprint) method from the FlexAnalysis software and manually checked. The experimentally measured peptide masses were compared with the theoretical tryptic peptides calculated from the sequence of $\mathrm{ACCO}$, with variable modifications of the cysteine residues to take into account the number of grafted labels in the protein. In unlabelled samples, $C$ residues may be free cysteines or a S-carbamidomethylcysteines (CAM-cys) if alkylated. In labelled samples, unlabelled $\mathrm{C}$ residues may be free cysteines (reduced form) or CAM ( MW 57.02). A grafted $P$ can be detected as (i) S-proxyl-cysteine (Prox-cys, MW 237.12, -O form) (ii) S-proxylcysteine-H (Prox-cys-H, MW 238.13, OH form) (iii) S-proxyl-cysteine-H2O (Prox-cys-H2O, MW 255.13) and (iv) S-proxyl-cysteine-plusH2O-H (Proxcys-H2O-H, MW 256.14). Consequently, the following mass increments were monitored throughout the set of experiments: (i) when starting material is a protein in its reduced form: 237.12 (Prox-cys), 238.13 (Proxcys-H), 255.13 (Prox-cys-H2O), 256.14 (Prox-cys-H2O-H) and (ii) when the starting material is alkylated with iodoacetamide: 180.10 (Prox-cys), 181.11 (Prox-cys-H), 198.11 (Prox-cys-H2O), 199.12 (Prox-cys-H2O-H).

\section{DEER and RIDME experiments}

To get better sensitivity and higher-quality distance distributions the proteins were placed in MOPS buffer $\mathrm{pH} 7$ prepared in $\mathrm{D}_{2} \mathrm{O}$. ${ }^{[35]}$ The final protein concentrations ranged from 80 to $100 \mu \mathrm{M}$. Glycerol-[D8] (30 \% v/v) was added to the samples before rapid freezing to avoid heterogeneous protein concentration. Co-substrates and cofactors were added anaerobically in a glove box $\left(<2 \mathrm{ppm} \mathrm{O}_{2}\right)$ at the following concentrations: ACC $5 \mathrm{mM}, \mathrm{HCO}_{3}^{-} 25 \mathrm{mM}$ and ascorbate $0.1 \mathrm{mM}$. For $\mathrm{Cu}(\mathrm{II})$-reconstituted enzyme, 0.9 equivalent of $\mathrm{Cu}(\mathrm{II})$ from a solution of $10 \mathrm{mM} \mathrm{CuSO}_{4}$ was added to the apo-enzyme solution.

Q-band pulsed EPR experiments were performed on an Elexsys E580 spectrometer (Bruker) using the EN 5107D2 resonator and equipped with an Oxford helium cryostat temperature regulation unit. The data were recorded at a temperature of $60 \mathrm{~K}$ for DEER and $20 \mathrm{~K}$ for RIDME experiments. For nitroxide-nitroxide distance measurements, a four pulse DEER sequence ${ }^{[20]}$ was run using pulse durations of $20 \mathrm{~ns}(\pi / 2$ pulse) and $40 \mathrm{~ns}$ ( $\pi$ pulse) with delays $\tau_{1}$ of $200 \mathrm{~ns}$ and $\tau_{2}$ adjusted according to $\mathrm{T}_{\mathrm{m}}$. The pump frequency was set on the maximum of resonance and the observed one was $56 \mathrm{MHz}$ higher. To suppress undesirable echoes, an 8step phase cycle was applied. Data were collected during about $18 \mathrm{~h}$ for each sample. For $\mathrm{Cu}(\mathrm{II})$-nitroxide distance measurements, the five-pulse sequence RIDME[27] was run using pulse durations of $20 \mathrm{~ns}$ ( $\pi / 2$ pulse) and 40ns ( $\pi$ pulse) and an interpulse delay of $\tau_{1}=300 \mathrm{~ns}$ (between the first and second pulses). The initial time interval between the $4^{\text {th }}$ and $5^{\text {th }}$ pulses was 3300 ns. An 8-step phase cycle was applied to cancel unwanted echoes. The RIDME time traces were recorded at two different interpulse separations between the third and the fourth pulses: $\mathrm{T}_{\text {high }}=500 \mu$ s and $\mathrm{T}_{\text {low }}$ $=10 \mu \mathrm{s}$. Division of the time trace with $\mathrm{T}_{\text {high }}$ by the time trace with $\mathrm{T}_{\text {low }}$ leads to suppression of ESEEM artifacts peaks. ${ }^{[36]}$ Extraction of data from DEER and RIDME traces was performed using DeerAnalysis 2015 software. ${ }^{[37]}$ The dipolar evolution dataset after homogeneous 3D spin distribution background correction was processed with Tikhonov regularization to obtain inter-spin distributions. The regularization factor $\alpha$ was chosen according to the L-curve criterion, based on a compromise between smoothness and resolution. ${ }^{[38]}$

\section{Molecular dynamics - Model construction}

A model for the open form of ACCO (without ACC, ascorbate or bicarbonate) was constructed using chain A of the 1WA6 protein databank structure. ${ }^{[9]} \mathrm{A}$ break in one of the loops of the crystal structure was fixed using the SWISS-MODEL webserver. ${ }^{[39]}$ Additional C-terminal residues present in the sequence but missing in the crystal structure were added using the build function in PyMOL. Mutant structures $(\mathrm{C} 165 \mathrm{H} / \mathrm{L} 292 \mathrm{C}$ and C165H/M307C) were made by replacing sidechains using SCWRL4 software package. ${ }^{[40]}$ The LEaP module integrated in the Ambertools14 software package ${ }^{[41]}$ was used to add hydrogen atoms and solvate the protein with TIP3P water molecules in a periodic box with a volume of $81 \times 100 \times 90 \AA$. We used PROPKA 3 to ascertain an appropriate protonation state for all titratable residues at $\mathrm{pH}$ 7.0. ${ }^{[42]} \mathrm{All} \mathrm{Arg} / \mathrm{Lys}$ residues were protonated and all Glu/Asp residues were deprotonated. Histidine Fe ligands were protonated at $\mathrm{N} \delta$, while all other histidine residues were protonated at $\mathrm{N} \varepsilon$. Counter ions $\left(\mathrm{Na}^{+}\right.$and $\left.\mathrm{Cl}^{-}\right)$were added to the model in random positions to neutralise the system and create an ionic strength 0.15 M. Depending on the model, cysteine residues (C60, C292 or C307) were replaced with a cysteine with an attached paramagnetic probe (termed RCY) built using the Avogadro program. ${ }^{[43]} \mathrm{RCY}$ was hydrogenated as radicals are poorly described in molecular dynamics. Parameters and topology files for standard protein residues were generated using the ff14SB forcefield. Parameters and topology files for RCY residues were generated using the general AMBER force field (GAFF) with the Antechamber software package (part of Ambertools14). ${ }^{[44,45]}$ Partial charges were obtained using the AM1-BCC charge model. Parameters for the Fe centre were obtained from a DFT calculation in Gaussian-09 ${ }^{[46]}$ (method: B3LYP ${ }^{[47,48]}$ optimised with basis set: $6-31 G^{* *},{ }^{[49]}$ frequency calculation with basis set: $6-311++G(2 s p, f)$ ) which included the $\mathrm{Fe}$, methylated ligand sidechains and three water molecules (Table S4 \& Figure S8). Force constants were extracted from the frequency calculation using the VFFDT software. ${ }^{[50]}$ Partial charges were obtained from the electrostatic potential at points selected according to the Merz-Singh-Kollman scheme, ${ }^{[51]}$ which were then RESP fitted. ${ }^{[52]}$

A model for the closed form of ACCO was obtained from a previously published study. ${ }^{[13]}$ This model also included docked positions of ACC, ascorbate and bicarbonate which were included in our simulations of the closed form. A WT model was constructed using the same procedure as for the open form. Two mutant models (C165H/L292C and C165H/M307C) were also constructed using the same procedure but using snapshots from a WT simulation at 50, 100 and $150 \mathrm{~ns}$ in order to achieve slightly different conformations of the closed structure. Additional parameters and topology files for ACC, ascorbate and bicarbonate were generated using the GAFF using the Antechamber software package.

Topology and parameter files generated for the iron(II) centre and RCY are provided in supporting information (Table S5)

\section{Molecular dynamics - Simulations}

Molecular dynamics simulations were performed using the GPUaccelerated AMBER PMEMD program on a NVIDIA K20 GPU. ${ }^{[41]}$ Solvent and ion positions were minimised for a maximum of 1000 steps switching from the steepest descent algorithm to conjugate gradient after 500 steps whilst restraining protein atoms with a force constant of $500 \mathrm{kcal} \mathrm{mol}^{-1} \AA^{-}$ 2. A second step of minimisation was then performed for 2500 steps, switching minimization algorithms after 1000 steps, with restraints on protein atoms reduced to $2 \mathrm{kcal} \mathrm{mol}^{-1} \AA^{-2}$. The cut-off for non-bonded interactions was $16 \AA$ during both minimization procedures. The system was heated from 0 to $300 \mathrm{~K}$ over a period of $200 \mathrm{ps}$ at constant volume with restraints on protein atoms $\left(2 \mathrm{kcal} \mathrm{mol}^{-1} \AA^{-2}\right)$. 200 ps density equilibration with the same restraints on the protein was followed by a further $200 \mathrm{ps}$ of equilibration without restraints at constant temperature and pressure. For each model, three production runs were produced at constant temperature and pressure for $200-400 \mathrm{~ns}$. The total simulation time for each of the variants was $1.2 \mu \mathrm{s}$ for C60 C292 and C60 C307 open forms and $0.6 \mu \mathrm{s}$ for C60 C292 and C60 C307 closed forms. Long-range electrostatics were computed with the particle mesh Ewald scheme. The cut-off for nonbonded interactions was $8.0 \AA$. The SHAKE algorithm was used to constrain bonds involving hydrogen to allow for a 2 fs time step. A Langevin thermostat was used to maintain a temperature of $300 \mathrm{~K}$ using a collision frequency of 2.0 $\mathrm{ps}^{-1}$ and a Berendsen barostat was used to maintain pressure of $1 \mathrm{~atm}$. Trajectories were processed with the CPPTRAJ program. ${ }^{[52]}$ The RMSD plots for the simulations are provided Figures S9 \& S10. 


\section{Acknowledgements}

This work was supported by A*MIDEX (ANR-11-IDEX- 0001-02) funded by the «Investissements d'Avenir » French Government program and Aix-Marseille Universite (AMU). The authors are grateful to the EPR facilities available at the Aix-Marseille Université, to the Conseil Régional of PACA and the city of Marseille for financial support in the acquisition of equipment. Financial support from the TGE RPE FR3443 for conducting the research is gratefully acknowledged. EF is grateful to $A^{*} M I D E X$ and Aix-Marseille Université for her PhD Fellowship. NJF and SdV thank the BBSRC for a studentship (under grant code BB/J014478/1).

Keywords: Enzyme structure and dynamics - ethylene • Molecular Dynamics $\cdot$ Electron paramagnetic resonance $\cdot$ ACC Oxidase $\cdot$ paramagnetic labelling

[1] A. B. Bleecker, H. Kende, Annu. Rev. Cell Dev. Biol. 2000, 16, 1-18.

[2] D. O. Adams, S. F. Yang, Proc. Natl. Acad. Sci. U.S.A. 1979, 76, 170 174.

[3] M. Costas, M. P. Mehn, M. P. Jensen, L. Que, Chem. Rev. 2004, 104, 939-986.

[4] L. J. Murphy, K. N. Robertson, S. G. Harroun, C. L. Brosseau, U. WernerZwanziger, J. Moilanen, H. M. Tuononen, J. A. C. Clyburne, Science 2014, 344, 75-78.

[5] A. J. Simaan, M. Réglier, in 2-Oxoglutarate-Dependent Oxygenases (Eds.: R.P. Hausinger, C.J. Schofield), Royal Society of Chemistry, Cambridge, 2015, p. 425

[6] J. J. Smith, P. John, 1993, 32, 1381-1386.

[7] J. Zhou, A. M. Rocklin, J. D. Lipscomb, L. Que, E. I. Solomon, J. Am. Chem. Soc. 2002, 124, 4602-4609.

[8] A. M. Rocklin, K. Kato, H.-W. Liu, L. Que, J. D. Lipscomb, J Biol Inorg Chem 2004, 9, 171-182.

[9] Z. Zhang, J.-S. Ren, I. J. Clifton, C. J. Schofield, Chem. Biol. 2004, 11, 1383-1394.

[10] E. L. Hegg, L. Que, Eur. J. Biochem. 1997, 250, 625-629.

[11] S. Tachon, E. Fournier, C. Decroos, P. Mansuelle, E. Etienne, M. Maresca, M. Martinho, V. Belle, T. Tron, A. J. Simaan, Mol Biotechnol 2019, 16, 1-15.

[12] Y. S. Seo, A. Yoo, J. JUNG, S.-K. Sung, D. R. Yang, W. T. Kim, W. Lee, Biochemical Journal 2004, 380, 339-346.

[13] A. Yoo, Y. S. Seo, J.-W. Jung, S.-K. Sung, W. T. Kim, W. Lee, D. R. Yang, J Struct Biol 2006, 156, 407-420.

[14] L. Brisson, N. Bakkali-Taheri, M. Giorgi, A. Fadel, J. Kaizer, M. Réglier, T. Tron, E. H. Ajandouz, A. J. Simaan, J Biol Inorg Chem 2012, 17, 939 949.

[15] X. Sun, Y. Li, W. He, C. Ji, P. Xia, Y. Wang, S. Du, H. Li, N. Raikhel, J. Xiao, et al., Nat Commun 2017, 8, 15758-14.

[16] W. L. Hubbell, C. J. López, C. Altenbach, Z. Yang, Current Opinion in Structural Biology 2013, 23, 725-733.

[17] M. Martinho, E. Fournier, N. Le Breton, E. Mileo, V. Belle, in Electron Paramagnetic Resonance, Royal Society of Chemistry, Cambridge, 2018, pp. 66-88.

[18] H. S. Mchaourab, P. R. Steed, K. Kazmier, Structure 2011, 19, 1549 1561.

[19] M. M. Haugland, J. E. Lovett, E. A. Anderson, Chem. Soc. Rev. 2017, 113.

[20] M. Pannier, S. Veit, A. Godt, G. Jeschke, H. W. Speiss, J Magn Reson 2000, 331-340

[21] T. Schmidt, M. A. Wälti, J. L. Baber, E. J. Hustedt, G. M. Clore, Angew. Chem. 2016, 128, 16137-16141.

[22] J. M. Chalker, G. J. L. Bernardes, Y. A. Lin, B. G. Davis, Chem. Asian J. 2009, 4, 630-640.

[23] O. Boutureira, G. J. L. Bernardes, Chem. Rev. 2015, 115, 2174-2195.

[24] G. Jeschke, Protein Science 2018, 27, 76-85.
[25] D. L. Tierney, A. M. Rocklin, J. D. Lipscomb, L. Que, B. M. Hoffman, J. Am. Chem. Soc. 2005, 127, 7005-7013.

[26] N. El Bakkali-Taheri, S. Tachon, M. Orio, S. Bertaina, M. Martinho, V. Robert, M. Réglier, T. Tron, P. Dorlet, A. J. Simaan, Arch. Biochem Biophys. 2017, 623-624, 31-41.

[27] S. Milikisyants, F. Scarpelli, M. G. Finiguerra, M. Ubbink, M. Huber, J. Magn. Reson. 2009, 201, 48-56.

[28] M. G. Quesne, T. Borowski, S. P. de Visser, Chem. Eur. J. 2015, 22, 2562-2581.

[29] V. Belle, A. Fournel, M. Woudstra, S. Ranaldi, F. Prieri, V. Thomé, J. Currault, R. Verger, B. Guigliarelli, F. Carrière, Biochemistry 2007, 46, 2205-2214.

[30] J. C. Lewis, Acc. Chem. Res. 2019, 52, 576-584.

[31] K. Bavishi, D. Li, S. Eiersholt, E. N. Hooley, T. C. Petersen, B. L. M. X. Iler, N. S. Hatzakis, T. Laursen, Sci Rep 2018, 1-9.

[32] M. M. Haque, M. Bayachou, J. Tejero, C. T. Kenney, N. M. Pearl, S.-C. Im, L. Waskell, D. J. Stuehr, FEBS J. 2014, 281, 5325-5340.

[33] Z. Zhang, C. J. Schofield, J. E. Baldwin, P. Thomas, P. John, Biochem. J. 1995, 307, 77-85.

[34] S. M. Kelly, T. J. Jess, N. C. Price, Biochimica et Biophysica Acta (BBA) - Proteins and Proteomics 2005, 1751, 119-139.

[35] G. Jeschke, A. Bender, H. Paulsen, H. Zimmermann, A. Godt, J Magn. Res. 2004, 169, 1-12.

[36] D. Abdullin, F. Duthie, A. Meyer, E. S. Müller, G. Hagelueken, O. Schiemann, J. Phys. Chem. B 2015, 119, 13534-13542.

[37] G. Jeschke, V. Chechik, P. Ionita, A. Godt, H. Zimmermann, J. Banham, C. R. Timmel, D. Hilger, H. Jung, Appl Magn Reson 2006, 30, 473-498.

[38] T. H. Edwards, S. Stoll, J. Magn. Reson. 2016, 270, 87-97.

[39] A. Waterhouse, M. Bertoni, S. Bienert, G. Studer, G. Tauriello, R. Gumienny, F. T. Heer, T. A. P. de Beer, C. Rempfer, L. Bordoli, et al., Nucleic Acids Research 2018, 46, W296-W303.

[40] G. G. Krivov, M. V. Shapovalov, R. L. Dunbrack Jr., Proteins 2009, 77, 778-795.

[41] D. A. Case, V. Babin, J. Berryman, R. M. Betz, Q. Cai, Amber 14, 2014.

[42] M. H. M. Olsson, C. R. Søndergaard, M. Rostkowski, J. H. Jensen, J. Chem. Theory Comput. 2011, 7, 525-537.

[43] M. D. Hanwell, D. E. Curtis, D. C. Lonie, T. Vandermeersch, E. Zurek, G R. Hutchison, J Cheminform 2012, 4, 17.

[44] J. A. Maier, C. Martinez, K. Kasavajhala, L. Wickstrom, K. E. Hauser, C. Simmerling, J. Chem. Theory Comput. 2015, 11, 3696-3713.

[45] J. Wang, W. Wang, P. A. Kollman, D. A. Case, Journal of Molecular Graphics and Modelling 2006, 25, 247-260.

[46] Gaussian 09, Revision B.01, M. J. Frisch, H. B. Schlegel, G. E. Scuseria, M. A. Robb, J. R. Cheeseman, G. Scalmani, V. Barone, G. A. Petersson H. Nakatsuji, X. Li, M. Caricato, A. Marenich, J. Bloino, B. G. Janesko, R.Gomperts, B. Mennucci, H. P. Hratchian, J. V. Ortiz, A. F. Izmaylov, J. L. Sonnenberg, D. Williams-Young, F. Ding, F.Lipparini, F. Egidi, J.Goings,B. Peng, A. Petrone, T. Henderson, D. Ranasinghe, V. G Zakrzewski, J.Gao, N. Rega, G. Zheng, W. Liang, M. Hada, M. Ehara, K. Toyota, R. Fukuda, J. Hasegawa, M. Ishida, T. Nakajima, Y. Honda, O Kitao, H. Nakai, T. Vreven, K. Throssell, J. A. Montgomery, Jr., J. E. Peralta, F. Ogliaro, M. Bearpark, J. J. Heyd, E. Brothers, K. N. Kudin, V. N. Staroverov, T. Keith, R. Kobayashi, J. Normand, K. Raghavachari, A. Rendell, J. C.Burant, S. S. lyengar, J. Tomasi, M. Cossi, J. M. Millam, M. Klene, C. Adamo, R. Cammi, J. W. Ochterski, R. L. Martin, K. Morokuma, O. Farkas, J. B. Foresman, D. J. Fox, Gaussian, Inc.,Wallingford CT, 2016.

[47] A. D. Becke, J. Chem. Phys. 1993, 98, 5648-5652.

[48] C. Lee, W. Yang, R. G. Parr, Phys. Rev. B 1988, 37, 785-789.

[49] P. J. Hay, W. R. Wadt, J. Chem. Phys. 1985, 82, 270-283.

[50] S. Zheng, Q. Tang, J. He, S. Du, S. Xu, C. Wang, Y. Xu, F. Lin, J. Chem. Inf. Model. 2016, 56, 811-818.

[51] B. H. Besler, K. M. Merz, P. A. Kollman, J Comput Chem 1990, 11, 431439.

[52] D. R. Roe, T. E. Cheatham III, J. Chem. Theory Comput. 2013, 9, 30843095 


\section{Entry for the Table of Contents}

\section{FULL PAPER}

A combined experimental and theoretical study was performed to unravel the conformation of the Cterminal part of ACCO

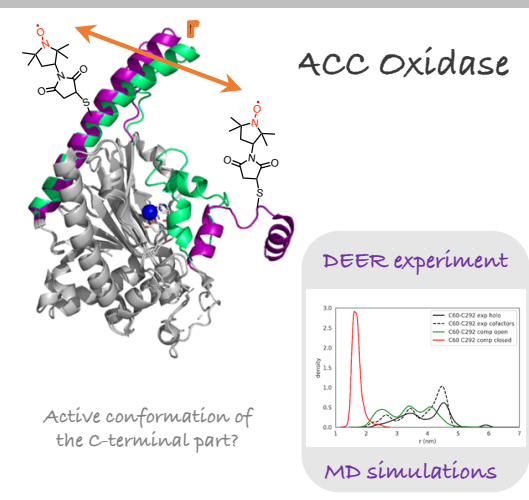

Eugénie Fournier, Sybille Tachon, Nicholas J. Fowler, Guillaume Gerbaud, Pascal Mansuelle, Pierre Dorlet, Sam P. de Visser, ${ }^{*}$ Valérie Belle, A. Jalila Simaan*and Marlène Martinho*

Page No. - Page No.

The hunt for the closed conformation of the fruit-ripening enzyme 1-amino-cyclopropane-1carboxylic oxidase: A combined EPR and MD study. 